\title{
Tetanus Toxoid Vaccination Coverage Among Women of Reproductive Age: Experience From a Rural Community
}

MZ Islam ${ }^{1}$, MS Ahmed ${ }^{2}$, A Nafiza ${ }^{3}$, S Farjana ${ }^{4}$, SK Mazumder ${ }^{5}$

\begin{abstract}
:
Tetanus Toxoid (TT) is a routine vaccination activity under Expanded Program on Immunization (EPI) in Bangladesh. The women of reproductive age (15-49 years) are the target population for five doses of TT vaccine to protect them from tetanus. The study was a cross-sectional study in context of a rural community. The study was conducted to assess TT vaccination coverage among the women of reproductive age in a rural community of Bangladesh. A total of 224 women of reproductive age were randomly included in the study following selection criteria. Data was collected by recall history and reviewing immunization card by using a semi-structured questionnaire and checklist respectively. Data was processed and analyzed considering both descriptive and inferential statistics. Mean age of the women was $27.22 \pm 6.87$ years and major part (30.4\%) was illiterate. Most of the women were married (87.6\%) and housewives (81.3\%). Mean age at marriage was 17+2.37 years and mean age at first child birth was $18+2.24$ years. On the basis of recall history and vaccination card, $83.5 \%$ women received first dose of TT (TT1), while 16.5\% didn't receive any TT vaccine. Among the women received all five doses of TT, 'Crude Vaccination Rate" was 37.0\% and "Valid Vaccination Rate' was $33.0 \%$. By card, these rates were $18.5 \%$ and $14.2 \%$ respectively. The invalid doses found $6.2 \%$ for TT2, $7.3 \%$ for TT3, $12.5 \%$ for TT4 and the lowest $10.8 \%$ for TT5 dose. The dropout rate was $5.3 \%$ for TT1-TT2, 14.7\% for TT2-TT3, the highest 31.1\% for TT3-TT4 and 20.2\% for TT4-TT5 while 55.6\% was for TT1-TT5. Vaccination coverage was significantly higher among the women aged 25-29 years (91.0\%) and having HSC level education (92.3\%) ( $x^{2}$ test, $\left.p<0.05\right)$. An incredible segment of rural women didn't receive any dose of TT5 vaccine and dropout rate was significantly higher among poor and illiterate women. Painstaking interventions and strategies should be taken to increase TT5 vaccination coverage among the rural women to protect them from tetanus.
\end{abstract}

1. Dr. Md. Ziaul Islam, Associate Professor, Department of Community Medicine, (NIPSOM), Mohakhali, Dhaka.

2. Dr. Md. Sharfuddin Ahmed, Chairman and Head, Department of Ophthalmology, BSMMU.

3. Dr. Nafiza Ahmed, MBBS, Assistant Professor, Dermatology, Dhaka Medical College Hospital.

4. Dr. Sharmin Farjana, Medical Officer, Upazila Health Complex, Nandail, Mymensingh.

5. (Dr.) Saroj Kumar Mazumder, Director, NIPSOM, Mohakhali, Dhaka.

\section{Corresponding Author:}

Dr. Md. Ziaul Islam, Associate Professor, Department of Community Medicine, (NIPSOM), Mohakhali, Dhaka.

e-mail: ziauliph67@yahoo.com,dr.ziaul.islam@gmail.com.
Key words: TT vaccination, women of reproductive age, rural community, dropout.

\section{Introduction:}

Tetanus Toxoid (TT) is administered to women of reproductive age (15-44 years) to protect them from tetanus and their newborn babies from neonatal tetanus. Neonatal tetanus is a grave disease caused by a bacterial pathogen transmitted during the childbirth usually in an unhygienic condition. ${ }^{1,2}$ A woman needs a total of 5 TT doses for life long protection from tetanus and all the doses should be administered according to the WHO-recommended schedule. Since only one TT dose does not offer any protection, a woman needs at least two doses TT vaccine (TT1 and TT2), to get some protection. ${ }^{3,4}$ Females are more exposed to the risk of tetanus, especially during unsafe home delivery or abortion by untrained birth attendance and suffer from "puerperal tetanus". Neonates typically contact the disease during birth, when delivered in unhygienic conditions, especially when the umbilical cord is managed by unclean instruments and substances like ashes, soil or cow dung. 5,6

Tetanus is a preventable disease. No age is immune unless protected by previous immunization. Tetanus Toxoid is highly effective and lasts for several years. Patients who have recovered from tetanus must be actively immunized, because the amounts of toxin responsible for the disease in man do not stimulate protective immunity. ${ }^{7,8}$ Protection by TT vaccination begins 15 days after the second dose and completion of 5 doses of TT vaccination in schedules ensure immunity during whole reproductive life of the women. 9,11

In Bangladesh two major vulnerable groups for tetanus; pregnant women and neonates reside in rural part of the country. Tetanus Toxoid is an ongoing vaccination program under EPI in Bangladesh and the target population of this program is women of reproductive age. Success of the program results decrease in mortality of bother and newborn from tetanus. ${ }^{12}$ Since it is difficult to ensure clean deliveries in the developing countries like Bangladesh, immunization of mother against tetanus has been a more reliable method to prevent neonatal tetanus and postpartum tetanus. The Government of Bangladesh launched EPI programme on 7th April, 1979 with special global agenda to immunize all the women of reproductive age. ${ }^{13,14}$

It is evidenced that TT vaccination coverage is still very poor along with high dropout rate in rural part of the country. This present study was designed to assess the TT vaccination coverage, dropout rate and related reasons to contribute the improvement of TT vaccination coverage among the rural women of the country. improvement of TT vaccination coverage among the rural women of the country. 


\section{Materials and Methods:}

The cross-sectional study was conducted among 224 women of reproductive age (15-49) during the period of January to June, 2009 at Boro Chandrail village of Dhamrai upazila under Dhaka District. Study subjects were selected randomly following selection criteria. Data was collected by face-to-face interview and reviewing vaccine card with the help of a semi-structured questionnaire and checklist respectively. Data was processed marinating quality control check.

Considering both recall history and reviewing immunization card, crude TT coverage was assessed in terms of all TT doses, both valid and invalid, that a woman received. Any TT dose administered before the recommended interval after a duly administered TT dose was considered as invalid TT dose. Women received all five doses of TT vaccine irrespective of recommended interval were considered as 'Crude vaccination' and women received all five doses of TT vaccine following recommended interval were considered as 'Valid vaccination'.

ata was analyzed by using the SPSS soft-ware (version-17.0). Descriptive statistics like frequency distribution, percentage and mean $( \pm \mathrm{SD})$ were estimated along with statistical association was evaluated with TT vaccination coverage. Vaccination coverage (both crude and valid), invalid doses, dropout rate, reasons of dropout and no vaccination were estimated separately in respect of different doses. Group comparisons were made using 't' test. All ' $p$ ' values presented are two tailed.

Participation of the respondents in this study was ensured by their Informed Consent and it did not do any physical, mental, social and economical harm to them. Information was dealt with confidentiality and was used for this study only. They had preserved full freedom to withdraw their consent at any time and at any stage of this study.

\section{Results:}

Majority of the women (39.3\%) was in the age group of 20 to 24 years and their mean age was 27.22 ( 6.87) years. By education, majority (30.4\%) was illiterate followed by $29.5 \%$ with primary level education. Most of them $(81.3 \%)$ was housewives and had poor average monthly family income Tk.7,542.15 (+2,566.4). Most of the women (87.6\%) were married with mean age of marriage $17(+2.37)$ years. Mean age of first child birth was $18+2.24$ yrs and most of them $(76.4 \%)$ were residing in joint family as depicted in table-I.
Table-I: Background Characteristics of the Rural Women $(\mathrm{n}=224)$

\begin{tabular}{|c|c|}
\hline Attribute & Finding \\
\hline $\begin{array}{l}\text { Age group } \\
\text { (in years) }\end{array}$ & $\begin{array}{l}15-19=19.6 \%, 20-24=39.3 \%, 25-29=24.6 \%, 30-34= \\
8.9 \%, 35-39=7.6 \% ; \text { Mean }( \pm S D)=27.22( \pm 6.87)\end{array}$ \\
\hline Edu & $\begin{array}{l}\text { Illiterate }=30.4 \% \text {, Primary }=29.5 \% \text {, Secondary }=20.1 \%, \\
\text { SSC \& equivalent }=14.3 \%, \text { HSC \& equivalent }=4.0 \%, \\
\text { Graduate \& above }=1.7 \% .\end{array}$ \\
\hline Occ & $\begin{array}{l}\text { House wife }=81.3 \% \text {, Service }=7.5 \% \text {, Business }=2.4 \% \text {, } \\
\text { Farmer }=4.6 \% \text {, Student }=4.2 \% .\end{array}$ \\
\hline $\begin{array}{l}\text { Monthly family income (in } \\
\text { Ta ka.) }\end{array}$ & $\begin{array}{l}\text { Tk.2000 }-5000=33.8 \%, \text { Tk.5001 }-10,000=54.7 \% \text {, } \\
\text { Tk.10,001 }-20,000=11.5 \%, \text { Mean }( \pm S D)= \\
\text { Tk. } 7,542.15 \pm 2,566.4 .\end{array}$ \\
\hline Marital status & $\begin{array}{l}\text { Married } / \text { Widow } / \text { Divorced } / \text { Separated }=87.6 \%, \\
\text { Unmarried } \quad=12.4 \%)\end{array}$ \\
\hline $\begin{array}{l}\text { Age at marriage } \\
\text { (in years) }\end{array}$ & $\begin{array}{l}11-17=60.7 \%, 18-21=33.4 \%, 22 \quad-25=5.9 \%, \text { Mean age } \\
( \pm S D)=17 \pm 2.37 \text { years }\end{array}$ \\
\hline $\begin{array}{l}\text { Age at first child birth } \\
\text { (in years) }\end{array}$ & $\begin{array}{l}16-18=64.8 \%, 19-25=32.6 \%, 26 \quad-30=2.6 \%, \text { Mean age } \\
( \pm S D)=18 \quad \pm 2.24 y \text { ea rs }\end{array}$ \\
\hline Family type & Nuclear family $=23.6 \%$, Joint Family $=76.4 \%$ \\
\hline
\end{tabular}

The study showed that $83.5 \%$ women received TT1, $79.0 \%$ received TT2 followed by $67.4 \%$ and $46.4 \%$ received TT3 and TT4 respectively while $37.0 \%$ received TT5 as crude vaccination, which is focused in table-II. On the other hand, depending on card findings, valid vaccination was $83.5 \%$ for TT1, $74.2 \%$ for TT2, $62.5 \%$ for TT3, $40.5 \%$ for TT4 and $33.0 \%$ for TT5, which is reflected in table-III.

Table-II: Crude and Valid TT Vaccination (Card + History) Coverage $(\mathrm{n}=224)$

\begin{tabular}{|c|c|c|}
\hline \multirow{2}{*}{ Dose of TT } & \multicolumn{3}{|c|}{ Coverage (Card + History) } \\
\cline { 2 - 3 } & Crude f (\%) & Valid f (\%) \\
\hline TT1 & $187(83.5)$ & $187(83.5)$ \\
\hline TT2 & $177(79.0)$ & $166(74.2)$ \\
\hline TT3 & $151(67.4)$ & $140(62.5)$ \\
\hline TT4 & $104(46.4)$ & $091(40.5)$ \\
\hline TT5 & $083(37.0)$ & $074(33.0)$ \\
\hline
\end{tabular}

Table-III: Crude and Valid TT Vaccination (Card Only) Coverage $(n=224)$

\begin{tabular}{|c|c|c|}
\hline \multirow{2}{*}{ Dose of TT } & \multicolumn{2}{|c|}{ Coverage (Card) } \\
\cline { 2 - 3 } & Crude f(\%) & Valid f(\%) \\
\hline TT1 & $102(45.5)$ & $95(42.4)$ \\
\hline TT2 & $95(42.4)$ & $91(40.6)$ \\
\hline TT3 & $86(38.4)$ & $79(35.3)$ \\
\hline TT4 & $68(30.3)$ & $57(25.4)$ \\
\hline TT5 & $41(18.3)$ & $32(14.3)$ \\
\hline
\end{tabular}


In respect of source of vaccination, majority (77.5\%) of the women received vaccine from GOB EPI Outreach centre followed by $16.6 \%$ from GOB hospitals, $4.3 \%$ from NGO facilities and only $1.6 \%$ from private chambers, which focused in figure- 1 .

Fig - 1: Distribution as per vaccination source $(n=187)$

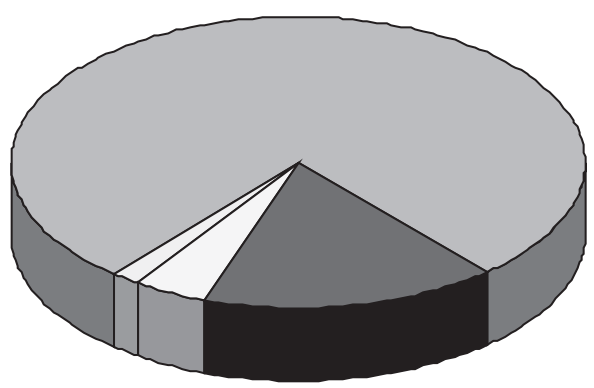

\section{$\square$ GOB EPI Outreach Centr $\square$ GOB Hospital $\square$ NGO Facilities $\square$ Private Chamber}

The study exposed that the interval between the consecutive doses for making an assessment of the proportion of TT doses administered not following the exact time and interval. The proportion of invalid doses found $6.2 \%$ for TT2, 7.3\% for TT3 dose, $12.5 \%$ for TT4 dose and the lowest $10.8 \%$ for TT5 dose, which is portrayed in table-IV.

Table-IV: Invalid TT vaccination by interval between consecutive doses

\begin{tabular}{|c|c|c|c|c|c|c|c|}
\hline Dose & $<4$ week & 4 week+ & $<6$ month & $\mathbf{6}$ month + & $<1$ year & $\mathbf{1}$ Year + & Total \\
\cline { 2 - 8 } Int erval & $\mathbf{f}(\%)$ & $\mathbf{f}(\%)$ & $\mathbf{f}(\%)$ & $\mathbf{f}(\%)$ & $\mathbf{f}(\%)$ & $\mathbf{f}(\%)$ & $\mathbf{f}(\%)$ \\
\hline TT1 -TT2 & $11(6.2)$ & 166 & & & & & $177(100.0)$ \\
& $(93.8)$ & & & & & \\
\hline TT2 -TT3 & & & $11(7.3)$ & $140(92.7)$ & & & $151(100.0)$ \\
\hline TT3 -TT4 & & & & & $13(12.5)$ & $91(87.5)$ & $104(100.0)$ \\
\hline TT4 -TT5 & & & & & $9(10.8)$ & $74(89.2)$ & $83(100.0)$ \\
\hline
\end{tabular}

Dropout rate of vaccination is shown in fig 2 . While calculation irrespective of valid and invalid vaccination, women were considered vaccinated. Forty four out of 187 $(44.4 \%)$ received all the five doses of vaccine and are expected to achieved life long immunized against tetanus.

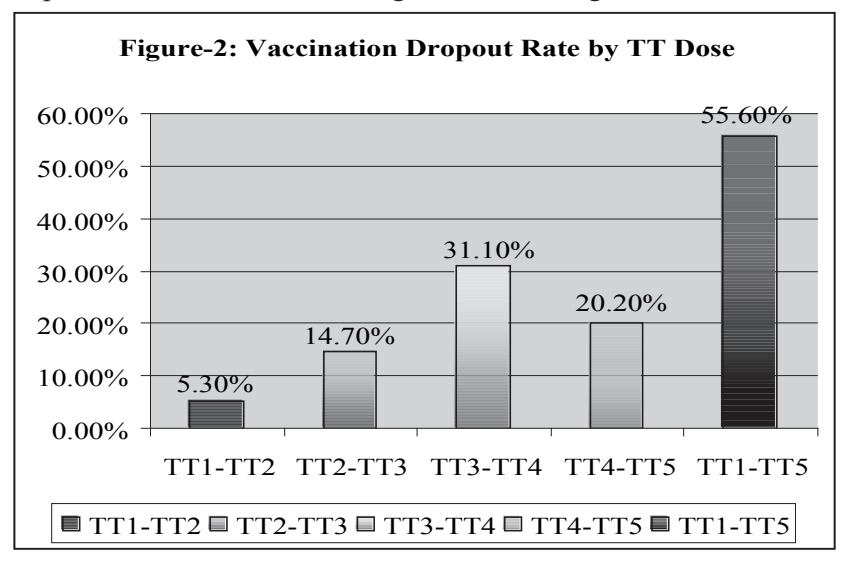

The study exposed that women between 25-29 years were more likely to receive TT vaccine as around $91.0 \%$ of the women in this age group received TT vaccine. On the contrary, the proportion of women who never received TT vaccine was the highest in the age group of 35-39 years as $29.4 \%$ women in this age group didn't receive any dose of TT vaccine (Table V).

Table-V: Receiving TT Vaccine by Age Group

\begin{tabular}{|r|c|c|c|}
\hline \multirow{2}{*}{ Age Group } & Received & Never Received & \multirow{2}{*}{$\begin{array}{c}\text { Total } \\
\mathbf{f ~ ( \% )}\end{array}$} \\
\cline { 2 - 3 } & $\mathbf{f}(\mathbf{\%})$ & $\mathbf{f}(\mathbf{\%})$ & \\
\hline $15-19$ & $36(81.8)$ & $08(18.2)$ & $44(100.0)$ \\
\hline $20-24$ & $75(85.2)$ & $13(14.8)$ & $88(100.0)$ \\
\hline $25-29$ & $50(90.9)$ & $05(09.1)$ & $55(100.0)$ \\
\hline $30-34$ & $14(79.9)$ & $06(20.1)$ & $20(100.0)$ \\
\hline $35-39$ & $12(70.6)$ & $05(29.4)$ & $17(100.0)$ \\
\hline Total & $187(83.5)$ & $37(16.5)$ & $224(100.0)$ \\
\hline Significance & $\left(\chi^{2}\right.$ test,$\left.p<0.05\right)$ & \\
\hline
\end{tabular}

It was emerged that women with HSC and above education were more likely to receive TT vaccine as $92.3 \%$ of the women of this group received TT vaccine. On the contrary, the proportion of women who never received TT vaccine was the highest $(23.5 \%)$ in the illiterate group of the women (Table-VI).

Table-VI: Receiving TT Vaccine by Educational Level $(\mathrm{n}=224)$

\begin{tabular}{|c|c|c|c|}
\hline \multirow[t]{2}{*}{ Education } & Received & Never Received & \multirow{2}{*}{$\begin{array}{l}\text { Total } \\
\mathrm{f}(\%)\end{array}$} \\
\hline & $f(\%)$ & $f(\%)$ & \\
\hline Primary & $54(81.8)$ & $12(18.2)$ & $66(100.0)$ \\
\hline Secondary & $40(88.9)$ & 05 (11.1) & $45(100.0)$ \\
\hline SSC\& equivalent & $29(90.6)$ & $03(09.4)$ & $32(100.0)$ \\
\hline HSC \& above & $12(92.3)$ & $01(07.7)$ & $13(100.0)$ \\
\hline Illiterate & $52(76.5)$ & $16(23.5)$ & $68(100.0)$ \\
\hline Total & $187(83.5)$ & $37(16.5)$ & $224(100.0)$ \\
\hline Significance & \multicolumn{3}{|l|}{$\left(\chi^{2}\right.$ test, $\left.\mathrm{p}<0.05\right)$} \\
\hline
\end{tabular}

The reasons for dropout included lack of information, lack of motivation and different obstacles. In respect of lack of information, majority of the women quoted 'lack of awareness of need and importance of TT immunization' $(54.4 \%)$. Detail is focused in table-VII. 
Table-VII: Distribution of the Reasons of dropout from TT Vaccination $(\mathrm{n}=104)$

\begin{tabular}{|l|l|c|}
\hline \multicolumn{1}{|c|}{ Sources } & \multicolumn{1}{|c|}{ Reasons } & Percentage \\
\hline \multirow{4}{*}{$\begin{array}{l}\text { Inform of } \\
\text { Intion }\end{array}$} & $\begin{array}{l}\text { Unaware of need \& importance for } \\
\text { immunization }\end{array}$ & 54.4 \\
\cline { 2 - 3 } & Unaware of need to return for next dose & 48.5 \\
\cline { 2 - 3 } & Place and/or time of immunization unknown & 28.7 \\
\cline { 2 - 3 } & Fear of side reactions & 16.6 \\
\cline { 2 - 3 } & Wrong ideas about contraindications & 12.4 \\
\hline \multirow{5}{*}{ Obstack of Motivation } & Postponed until another time & 06.5 \\
\cline { 2 - 3 } & No faith in immunization & 15.4 \\
\cline { 2 - 3 } & Rumors & 03.7 \\
\hline & Place of immunization too far to go & 16.7 \\
\cline { 2 - 3 } & Time of immunization inconvenient & 27.3 \\
\cline { 2 - 3 } & Cold Chain breakdown & 02.4 \\
\cline { 2 - 3 } & Vaccine shortage & 02.4 \\
\cline { 2 - 3 } & Outreach sessions infrequent & 04.4 \\
\cline { 2 - 3 } & Health staff perceived as "unfriendly" & 09.6 \\
\cline { 2 - 3 } & Not informed of outreach dates & 12.8 \\
\cline { 2 - 3 } & No active follow up of defaulters & 03.5 \\
\cline { 2 - 3 } & Family problem & 10.6 \\
\cline { 2 - 3 } & Long waiting time & 02.7 \\
\hline
\end{tabular}

*Multiple responses

The reasons for never TT vaccination included 54.4\% women didn't know about the need of vaccination, 38.3\% didn't think it necessary and other reasons are reflected in the table-VIII.

Table-VIII: Distribution of the Reasons of Never TT Vaccination $(n=37)$

\begin{tabular}{|l|c|}
\hline Reasons & Percentage \\
\hline Fear of TT & 24.6 \\
\hline Don't think it necessary & 38.3 \\
\hline Husband and family member doesn't like & 12.6 \\
\hline Don't know the need of vaccination & 54.4 \\
\hline Will receive vaccination in future & 16.7 \\
\hline
\end{tabular}

*Multiple responses

\section{Discussion:}

The cross-sectional study was conducted among women of reproductive age of a rural community to find out the scenario of TT5 vaccination. Regarding background characteristics, majority of the women (around 64.0\%) was young adult (20-29 years). Majority was either illiterate $(30.4 \%)$ or had primary education $(29.5 \%)$, was married $(87.6 \%)$ and house wives $(81.3 \%)$. Majority of the women (76.4\%) were residing in joint family with poor family income (Tk.7,542.15 + 2,566.4). Majority of the women gave first child birth at early age. All these findings represented the findings of the survey conducted by Nielsen Company. ${ }^{10}$ and IOCH. ${ }^{11}$
Considering both recall history and vaccination card, the study found that $83.5 \%$ women received TT1, $79.0 \%$ received TT2 followed by $67.4 \%$ and $46.4 \%$ received TT3 and TT4 respectively. Among the women, a remarkable part (16.5\%) never received TT vaccine while $37.0 \%$ received all five doses of TT vaccine irrespective of recommended interval (Crude vaccination) and $33.0 \%$ women received all five doses of TT vaccine following recommended interval (Valid vaccination). Considering card only, the crude and valid TT vaccination coverage was $18.3 \%$ and $14.3 \%$ respectively. These findings were very close to the findings of survey of the Nielsen Company in 2010, which found $90.0 \%$ women received TT1 vaccine followed by $37.0 \%$ crude vaccination coverage and $31.0 \%$ valid vaccination coverage among the women of Chittagong hill tracts. ${ }^{10}$

It was found that $77.5 \%$ women received $\mathrm{TT}$ vaccine from GOB EPI outreach centers followed by $16.6 \%$ from different GOB hospitals, $4.3 \%$ from NGO hospitals/clinics/ outreach centers and only $1.6 \%$ from private chambers of doctors. The study finding was consistent with the findings of the study conducted by $\mathrm{IOCH}$ in tea garden where most of the women received TT vaccine from GOB outreach centers. ${ }^{11}$

The proportion of invalid doses found $6.2 \%$ for TT2, 7.3\% for TT3 dose, $12.5 \%$ for TT4 dose and the lowest $10.8 \%$ for TT5 dose. The dropout rate was $5.3 \%$ for TT1-TT2, $14.7 \%$ for TT2-TT3, $20.2 \%$ for TT3-TT4 and the highest i.e. $31.1 \%$ was for TT4 -TT5. Overall dropout rate was $55.6 \%$ for TT1-TT5, which reflected that $55.6 \%$ women who received TT1 didn't get fully immunized for life-long protection against tetanus. The study conducted by $\mathrm{IOCH} .{ }^{11}$ found the highest dropout rate $(63.0 \%)$ for TT1-TT5 and the study conducted by Khan MN et all. ${ }^{13}$ found $66.0 \%$ dropout for TT1-TT5. This variation may be due to variation study places.

The study unmasked that women between 25-29 years were more likely to receive TT vaccine $(91.0 \%)$ while the proportion of women who never received TT vaccine was the highest $(29.4 \%)$ in the age group of 35-39 years and it was the lowest $(9.1 \%)$ in the age group between 25-29 years and this variation was statistically significant (?2test, $\mathrm{p}<0.05)$. Similar finding was emerged by the Nielsen study 10 where highest coverage $(93.0 \%)$ was in the age group 30-34 years while $22.0 \%$ was in the age group $>35$ years among the women who didn't receive any TT vaccine. ${ }^{10}$ It was found that proportion of women received TT vaccine was the highest $(92.3 \%)$ in the HSC and above education group while it was lower $(76.5 \%)$ in the illiterate group. On the contrary, the proportion of women who never received TT vaccine was significantly higher $(23.5 \%)$ in the illiterate group in comparison to the HSC and above education group (7.7\%), $\left(x^{2}\right.$ test, $\left.\mathrm{p}<0.05\right)$. In this respect the Nielsen study. ${ }^{10}$ showed higher incidence of invalid doses for TT3 while this current study found it for TT4 dose.

Reasons for dropout included lack of awareness of need and importance of TT immunization' (54.4\%), 'unaware of need to return for 2nd and 3rd dose' $(48.5 \%)$, 'place and/or time of immunization unknown' (28.7\%), 'fear of side reactions' $(16.6 \%)$ and 'wrong ideas about contraindications' (12.4\%) as 
the reasons for dropout. Lack of motivation included 'no faith in immunization' (15.4\%), 'postponed until another time' $(6.5 \%)$ and rumors (3.7\%). Different obstacles included 'place of immunization too far to go' (16.7\%), 'time of immunization inconvenient' $(27.3 \%)$, 'not informed of outreach dates' (12.8\%), 'family problem' (10.6\%) and 'health staff perceived as unfriendly' $(9.6 \%)$. Similar findings were noticed by the IOCH study. ${ }^{11}$ Regarding reasons for never vaccination, the women addressed 'fear of TT' (24.6\%), 'don't think it necessary' (38.3\%), 'husband and family member doesn't like' (12.6), 'don't know the need of vaccination' $(54.4 \%)$ and 'will receive vaccination in future' $(16.7 \%)$, which resembled the findings of Neilson study. ${ }^{10}$

\section{Conclusion:}

The study revealed that a significant part of the rural women of reproductive age never received TT5 vaccine. Among the vaccinated women, a remarkable part was dropped out due to different obstacles. Lack of awareness, poor education and economic condition were predominant reasons in this regard. The study recommends for effective strategies to increase TT5 vaccination coverage countrywide especially among vulnerable rural women.

\section{References:}

1. Council for international Organizations of Medical Sciences. Communicable Diseases. Provisional International Nomenclature/O. WHO: Geneva;

2. 1973.

David AW. Neonatal Tetanus and Birth Environment.

3. Medicine International 1981; 3: 118.

Louis WN. TT Vaccination and Immunity among Child

4. Bearing Women. Eng J Med 1973; 289: 1293.

Directorate General of Health Services (DGHS) and Ministry of Health and Family Welfare. Expanded

Programme on Immunization (EPI) Bulletin

5. 2009. EPI Headquarter, Mohakhali, Dhaka.

World Health Organization (WHO). Weekly Epidemiological Record, number 20. WHO: Geneva;
6. The Pocket Book of Statistics. Bangladesh Bureau of Statistics (BBS): Dhaka, Bangladesh; 2009.

7. National Institute of Population Research and Training (NIPORT), Mitra and Associates, and Macro International. Bangladesh Demographic and

Health Survey 2007. Dhaka, Bangladesh and Calverton,

8. Maryland, USA: March 2009

National Institute of Population Research and Training, Mitra and Associates, and Macro International.WWW.drugs.com. Drug

9. information on line: Tetanus Toxoid Vaccine. Viewed on 15th July, 2009.

Hosain GMM, Ahmed MK, Chowdhury Q. Tetanus

10. Toxoid Immunization among Women in Gono Shasthaya Kendra Area. www.icddr,b.com. Viewed on 15th July, 2009.

The Nielsen Company Bangladesh Limited. Report on Seventeen 30-Cluster EPI Coverage Evaluation 11. Survey in the Chittagong Hill Tracts. The Nielsen Company Bangladesh Limited: Dhaka, Bangladesh, 30th June $\quad 2010$; 30-36.

12. Immunization and Other Child Health Project. Vaccination Coverage Survey in the Tea Gardens Owned by the National/Local Companies.

13. Survey Report No. 59. D h a k a , Bangladesh, March 2002; 12-15.

World Health Organization (WHO). Facilitator Guide

14. for the EPI Coverage Survey for Training for Mid Level Managers. Geneva: WHO, 1991.

Khan MN, Rahman ML, Miah AA, Islam MS, Musa SA, Tofail F. Vaccination coverage survey in Dhaka District. Bangladesh Med Res Counc Bull 2005 Aug; 31(2): 46-53.

Adeiga A, Omilabu SA, Audu RA, Sanni F, Lakehinde 